\title{
Port Equipment Downtime Prediction and Lifetime Data Analysis: Evidence from a Case Study
}

\author{
Lot Okanminiwei ${ }^{1}$, Sunday Ayoola Oke ${ }^{1 *}$ \\ ${ }^{1}$ Department of Mechanical Engineering, University of Lagos, University Road Lagos Mainland Akoka, Yaba, \\ Lagos, Nigeria
}

Received: 27 October, 2020 / Accepted: 17 February, 2021

\begin{abstract}
Prediction of downtime and lifetime data for gantry cranes in a container terminal is a crucial concern for port terminals due to the requirement for maintenance planning and capital expenditure. Correct estimation of lifetime behavior for gantry cranes is complex since multiple cranes are involved, each with different costs, capacities; installation, and retirement dates. This paper develops statistically-oriented predictions for the lifetimes of container terminals company fleet of gantry cranes. Data records on downtime for cranes were collected and analyzed using Weibull, normal, and Rayleigh distributions regarding a port in southwestern Nigeria. The downtime, probability density function, cumulative density function, reliability, and hazard rate were analyzed for three shape functions of Weibull, $\beta=0.5,1$, and 3 . The same was analyzed for Rayleigh and normal distribution functions. The mean downtime was 30.58 hrs. The highest $P D F, C D F, R(t)$ for all $\beta=0.5,1$, and 3 , were 0.26, $0.78, .030$ and 13.13 , respectively. However, the least values for these parameters are 0.01, 0.71, 0.25, and 0.04, respectively. These values are means for thirty data points and concern the Weibull distribution function. For the Rayleigh distribution, the mean PDF, $C D F, R(t)$ and $h(t)$ are $0.002,0.042,0.958$ and 0.002 while they are 0.002, 0.456, 0.542 and 35.755 for the normal distribution. This article provides new insights into the lifetime analysis of gantry cranes in a container terminal.
\end{abstract}

Keywords: Container terminal, Weibull function, Normal distribution, Downtime, Rayleigh distribution

\section{INTRODUCTION}

Maintenance excellence in ports is a condition of port facilities and cargo handling equipment when the peak equipment reliability is guaranteed, top plant availability is attained at the least cost, and the quality goals and standards of cargo handling and delivery is ensured (Nyema, 2014; Keskinen, Annala and Miedema, 2017; Iyer and Nanyam, 2021). A port is an exact place in a maritime facility containing wharves where ships are docked (Chang, Shin and Lee, 2014; Jouili, 2016). In a port, passengers and cargo (commodities) are transported either between two water carriers or between land and water carriers. Terms that describe water carriers include docks, warehouses, sheds, wharves, yards, and piers. However, without attaining the optimal parametric values of the maintenance process, it is challenging to attain excellence in maintenance and the ports are at risk of substantial breakdown of equipment.
Knowledge of equipment downtime and the characteristics of failure of the gantry crane are essential to operate effectively. Undoubtedly, at present, literature studies on the attainment of maintenance excellence through the analysis of equipment failures for port equipment are extremely scarce.

Interestingly, the Weibull distribution, Rayleigh distribution, and normal distribution functions may be successfully deployed through the analysis of downtime and gantry crane characteristics to attain excellence in maintenance service. Weibull distribution is an effective tool to mode the lifetime of the gantry cranes to understand their reliability behavior. The Weibull function is characterized by the bathtub shape failure rate of three district regions burn-in (infant mortality), useful lifetime, and wear-out period. These regions respectfully experience decreased failure rates, quasi-constant failure rates, and increasing failure rates. The normal distribution is

*email: sa_oke@yahoo.com 
probability-based and may be effective to understand the ephemeron of lifetime data regarding the gantry crane. It is characterized by the mean and standard deviation, transforms data into a symmetrical arrangement such that major part clusters at the meanwhile the remaining data are shared towards a tapered pattern at the two extremes. The Rayleigh distribution is an approach used to analyze the dynamics behavior of phenomenon; it is applied to study the dynamic characteristics of downtime in the gantry crane.

Consequently, the port's maintenance activities should be analyzed regarding its failure behavior and enhanced to attain service excellence (Van Vianen et al., 2012; Cigolini, Pero and Rossi, 2013; Psaraftis and Kontovas, 2014; Yeo, Thai and Roh, 2015). Moreover, parametric values from maintenance activities may be benchmarked and the frequent labor disputes between the trade unions of the ports and management will be scientifically and robustly managed (Faltinova et al., 2018). Right now, repair activities, maintenance of port facilities, and cargo handling equipment are done by workers that adopt a blend of maintenance strategies, such as preventive maintenance, corrective maintenance, reliability-centered maintenance, breakdown maintenance, and overhaul during the year-ends. The work entails berth facility maintenance, port equipment maintenance, monitoring, training, and retraining of labor for productivity and planning for future expansion activities(Legato and Mazza, 2001; Nishimura, Imai and Papadimitriou, 2001; Yin, Khoo and Chen, 2011). In these activities, the maintenance manager works at sub-optimal levels instead of optimally achieving the set goals. Excellence in maintenance is not achieved as breakdown still occurs without proper predictions. The maintenance manager thus lacks knowledge of appropriate optimization tools for maintenance to be excellent. Excellence is achieved with the minimum breakdown at the predicted time and level. Excellence is also demonstrated when the maintenance staff works proactively and goaloriented. However, this may be aided with the knowledge and application of the failure analysis.

Sadly, the gap in failure data analysis may expand as more activities are added to the current capacity of ports' maintenance activities.
The urgency to bridge this research gap motivated the present authors to search for novel methods to resolve this problem. The study, therefore, presents the Weibull distribution, Rayleigh distribution, and normal distribution functions and their increasing acceptance in the literature has further driven this research for more validation of the models in the service setting. Excellent activities regarding repairs and maintenance of port facilities and cargo handling equipment are necessary for a developing country such as Nigeria to succeed in its trade regime (Adenigbo and Enyinda, 2016; Emenyonu et al., 2016). As Nigeria strives to compete in the world's export market, achieving excellence in maintenance through the deployment of Weibull distribution, Rayleigh distribution and normal distribution functions in container ports' maintenance is a compelling requirement.

Consequently, this article aims to develop a methodology based on the Weibull distribution, Rayleigh distribution, and Normal distribution functions to enhance the maintenance and repair activities of port facilities and cargo handling services and attain maintenance excellence in ports (Evans, Kretschmann and Green, 2019).

This article reacts to the pressing call by previous reports on the need for excellence in port operations (Yeo, Thai and Roh, 2015; Prpić-Oršić et al., 2016). It is thought that maintenance is a key aspect of the port's activities and attaining excellence in maintenance will certainly influence other units of the port's system. The response is through the contribution of the Weibull distribution, Rayleigh distribution, and normal distribution functions (Evans, Kretschmann and Green, 2019). The data used was collected from an operating port in Nigeria. The value brought by the study through the use of the Weibull distribution, Rayleigh distribution, and normal distribution functions is the ability to understand the responses toward an optimized port's maintenance operations.

From the foregoing, innovation has been brought to the maintenance of ports through the introduction of the Weibull distribution, Rayleigh distribution, and normal distribution functions as an intervention strategy for high performance. Previously, the complicated port maintenance activities, which ought to be 
optimized for performance excellence have been ignored and sub-optimal values of parameters are used for decision making. Nonetheless, this article introduces innovation through the Weibull distribution, Rayleigh distribution, and normal distribution functions for adoption in port activities. The outcome of this study will find usefulness to maintenance managers in ports as this paper transmits how the maintenance manager could set optimal maintenance parametric goals. This implies that the maintenance planning work will be enhanced and the manager attains success in the control of an organization that holds the key to the national economic progress of developing countries (Onwuegbuchunam, 2018; Sharapiyeva, Antoni and Yessenzhigitova, 2019).

In this work, the first part is an introduction and the current section serves this purpose, to explain the idea behind the work. It also addresses a review of the literature to create a relevant understanding of the gap that the research fills. The methodology that contains an outline of how the research will be carried out is indicated in the next section. The next part is the results and the last part gives a conclusion on the work.

\section{METHODOLOGY}

\subsection{The Weibull distribution}

Weibull distribution belongs to a statistical distribution group called continuous probability distribution and would be used to fit data to appraise container terminal equipment reliability, estimate the life data of gantry cranes and model the failure times of the cranes (Evans, Kretschmann and Green, 2019). Developed in 1951 by the Swedish researcher, Waloddi Weibull, it is known by different versions, including the two-parameter and threeparameter Weibull distribution. These important parameters are the shape parameter that is identified with the Weibull slope, the scale parameter that is associated with the features of the life, and the location parameter that is related to the waiting time. The phases in the implementation of Weibull distribution are (Evans, Kretschmann and Green, 2019):

Step 1: Collect the gantry crane downtime data and identify the data being transformed as internal data since it is collected over 30 weeks.
Step 2: Choose the Weibull lifetime distribution known to relate properly with the data and develop the model of the life of the gantry cranes.

Step 3: Establish the scale and shape parameters of the Weibull distribution.

Step 3.1: Compute the probability density function (PDF) of the gantry cranes.

Step 3.2: Calculate the cumulative density function of (CDF) of the gantry cranes.

Step 3.3: Compute the reliability function. Notice that this index examines the likelihood that the gantry cranes will continue to function when needed for loading or unloading activities at a specific point in time.

Step 3.4: Calculate the hazard function of the gantry cranes. This index reflects the rate of gantry crane failure over the 30 -week evaluation period. It shows the point in time that failures of the gantry cranes commence growing and the proportion within a specific interval.

Step 4: Develop tables or graphs which approximate the life features of the gantry cranes.

Step 5: Conclude on the results.

The important measures of this distribution are the probability density function (PDF), cumulative density function (CDF), reliability $R(t)$, and the hazard rate $h(t)$, represented mathematically as follows (Evans, Kretschmann and Green, 2019):

$$
\begin{gathered}
P D F=f(t)=\frac{\beta}{\eta}\left(\frac{t}{\eta}\right)^{\beta-1} e^{-\left(\frac{t}{\eta}\right)^{\beta}} \\
C D F=F(t)=1-e^{-\left(\frac{t}{\eta}\right)^{\beta}} \\
R(t)=1-F(t)=e^{-\left(\frac{t}{\eta}\right)^{\beta}} \\
h(t)=\frac{f(t)}{R(t)}
\end{gathered}
$$


Equations (1) to (4) were used to calculate the $\mathrm{PDF}, \mathrm{CDF}, R(t)$ and $h(t)$. The scale parameter, eta $\eta$, can be calculated to the 63.2 percentile downtime by noting Equation (5):

$$
\text { Percentile }=\left(\frac{P}{100}\right) N
$$

where $N$ is the number of weeks and $P$ is the value of eta $(\eta)$ at 63.2 percentile, and $\beta$ is the shape parameter.

The evaluation of $\eta$ is done as Percentile $=(63.2 / 100)(30 / 1)=18.96$, where the value of 30 is the total number of weeks considered. It follows that we need to consider the range between 18 and 19 weeks of downtime. The values extracted from the 18 and 19 weeks are averaged as $(26.09+4.29) / 2$, which gives $\eta$ as 15.19 .

The above equations were considered in the Normal distribution to the equipment downtime data as shown in the table below. However, the probability density function is given as Equation (6):

$$
P D F=F(t)=\frac{1}{\gamma \sqrt{2 \pi}} \exp \left[\frac{(t-x)^{2}}{2 \gamma^{2}}\right]
$$

The cumulative density function is given as Equation (7):

$$
\begin{aligned}
& C D F=F(t) \\
& =\frac{1}{\gamma \sqrt{2 \pi}} \int_{-\infty}^{t} \exp \left[\frac{(t-x)^{2}}{2 \gamma^{2}}\right] d x
\end{aligned}
$$

Reliability is given as Equations (8) and (9):

$$
\begin{gathered}
R(t)=\int_{t}^{\infty} f(t) d t \\
h(t)=\frac{f(t)}{R(t)}
\end{gathered}
$$

\subsection{The Rayleigh distribution}

Rayleigh distribution may be used to determine the gantry crane downtime characteristics as Equations (10) to (13):

$$
P D F=f(t) \theta=\frac{t}{\alpha^{2}} e^{\frac{t^{2}}{2 \alpha^{2}}}
$$

$$
\begin{gathered}
C D F=F(t) \alpha=y-e^{\frac{t^{2}}{2 \alpha^{2}}} \\
R(t)=e^{\frac{t^{2}}{2 \alpha^{2}}} \\
h(t)=\frac{f(t)}{R(t)}
\end{gathered}
$$

Equations (10) to (13) were used to determine the PDF, CDF, $R(t)$ and $h(t)$. In the Rayleigh distribution, it was discovered that the higher the downtime the lower the reliability. The mean and standard deviation were calculated:

Mean is the total downtime divided by the number of weeks while the standard deviation was obtained as Equation (14):

$$
\sigma=\sqrt{\frac{1}{n} \sum_{i=1}^{n}\left(x_{i}-\bar{x}\right)^{2}}
$$

The variance is calculated as the square of the standard deviation for the normal distribution method.

\section{RESULTS AND DISCUSSION}

The mobile gantry crane whose breakdown data is used for this study was collected from the maintenance section of a port operation in Nigeria. This equipment is used to handle cargo and containers during loading and discharging activities from the berths to ship and vice versa. In concurrence with the objective of this work, this data is analyzed with keen interest to understand the pattern of failures of the equipment. At the beginning point of data collection, the complex nature of port equipment was identified. It was noticed that safety was given the number one priority based on the heavy-duty equipment used in the port operation; it has huge investments in dollars regarding purchasing, installation, and annual maintenance costs. Efforts were made to understand the bottleneck equipment at the port. This critical equipment should normally be those without which the port productivity will decline if they failed to operate normally. The conclusion of the inquiring is that efforts should be directed only at the mobile harbor cranes 
since they determined the productivity of the port through the gross moves per hour count (GMPH) for any measurement period. Therefore, the scope of this work excludes the rubber tire gantry cranes, empty handlers, reach stackers, terminal trucks, and power generating plants, forklifts, and vehicle fleets. It is noted that if bottlenecks are experienced on the mobile harbor cranes, the port productivity will decline drastically with waiting trucks turned around period and cargo waiting for lifting operation. It is therefore sensible to pursue analysis only on the mobile harbor cranes to guarantee the efficiency of the port lifting operation.

Consequently, the maintenance data collected for eight specific cranes are labeled as MHC07, MHC08, MHC09, MHC10, MHC11, MHC12, MHC13, and MHC14. As such, for each of the mentioned cranes, weekly data on downtime was collected as shown in Table 1.

The weekly downtime data for the mobile harbor cranes for January 2016 to June 2016 are revealed. This study is novel, and no previous documentation had been made on downtime analysis concerning port operations in a developing country and Nigeria in particular. The novel aspect of this part of the work is a unique analysis of the downtime data for mobile harbor cranes. Available maintenance hours are obtained by the number of days the repairs were done in the week multiply by the total working hours per day from each of the cranes. The summarized downtime for cranes under study is shown in Table 2.

Table 1. Total Weekly Downtime Data for Mobile Harbor Cranes (Jan 2016-June 2016)

\begin{tabular}{ccccc}
\hline Equipment & Downtime & $\begin{array}{c}\text { Number of } \\
\text { repairs }\end{array}$ & $\begin{array}{c}\text { Available Maintenance } \\
\text { (hours) }\end{array}$ & MTTR \\
\hline MHC7 & 120.7 & 94 & 2160 & 1.3 \\
MHC8 & 80.4 & 107 & 2160 & 0.8 \\
MHC9 & 84.6 & 46 & 2160 & 1.8 \\
MHC10 & 51.5 & 93 & 2172 & 0.6 \\
MHC11 & 146.0 & 124 & 2160 & 1.2 \\
MHC12 & 151.1 & 192 & 2160 & 0.8 \\
MHC13 & 61.4 & 113 & 2160 & 0.5 \\
MHC14 & 51.5 & 148 & 2160 & 0.3 \\
\hline
\end{tabular}

Table 2.Total Downtime (Hours) of the Cranes Understudied

\begin{tabular}{cccc}
\hline Weeks & Downtimes (hrs:mins) & Weeks & Downtimes (hrs:mins) \\
\hline $\mathbf{1}$ & $6: 54$ & 16 & $21: 26$ \\
$\mathbf{2}$ & $18: 49$ & 17 & $14: 39$ \\
$\mathbf{3}$ & $21: 00$ & 18 & $26: 09$ \\
$\mathbf{4}$ & $16: 12$ & 19 & $4: 29$ \\
$\mathbf{5}$ & $20: 37$ & 20 & $21: 13$ \\
$\mathbf{6}$ & $33: 27$ & 21 & $33: 19$ \\
$\mathbf{7}$ & $124: 18$ & 22 & $58: 41$ \\
$\mathbf{8}$ & $68: 05$ & 23 & $22: 30$ \\
$\mathbf{9}$ & $17: 04$ & 24 & $36: 31$ \\
$\mathbf{1 0}$ & $25: 05$ & 25 & $22: 17$ \\
$\mathbf{1 1}$ & $20: 34$ & 26 & $26: 55$ \\
$\mathbf{1 2}$ & $13: 18$ & 27 & $19: 18$ \\
$\mathbf{1 3}$ & $23: 05$ & 28 & $42: 52$ \\
$\mathbf{1 4}$ & $35: 24$ & 29 & $52: 16$ \\
$\mathbf{1 5}$ & $24: 44$ & 30 & $51: 02$ \\
\hline
\end{tabular}


The probability density function (PDF) is one of the metrics used for all the three distribution functions that the failure data of the gantry crane is modeled after (Tables 3 and 4). The PDF was used to evaluate the attributes of Weibull distribution, Rayleigh distribution, and the Normal distribution.

In applying the PDF, the researchers are interested in understanding the likelihood of achieving the potential values, which a random variate of the gantry crane data can take on. By commencing the analysis on the Weibull function with $\beta=0.5$, the least value of PDF obtained, week 7 , is 0.00066 . This value is revealing the worst probability of the failure of the gantry crane. If the distribution representing this value is to be plotted, it means that the density is being plotted, the integral of the density function within a span of values, which is the added area under the curve, represents the probability density function of interest. However, the highest PDF when $\beta=0.5$ was obtained at 0.09 , which occurred as a tie in weeks 3 and 5 .

The probability density function (PDF) is one of the metrics used for all the three distribution functions that the failure data of the gantry crane is modeled after (Tables 3 and 4). The PDF was used to evaluate the attributes of Weibull distribution, Rayleigh distribution, and the Normal distribution. In applying the PDF, the researchers are interested in understanding the likelihood of achieving the potential values, which a random variate of the gantry crane data can take on. By commencing the analysis on the Weibull function with $\beta=0.5$, the least value of PDF obtained, week 7 , is 0.00066 . This value is revealing the worst probability of the failure of the gantry crane. If the distribution representing this value is to be plotted, it means that the density is being plotted, the integral of the density function within a span of values, which is the added area under the curve, represents the probability density function of interest. However, the highest PDF when $\beta=0.5$ was obtained at 0.09 , which occurred as a tie in weeks 3 and 5 .

The reliability index, otherwise reflecting the survival attribute of the gantry cranes indicates a value of 0.06 and 0.31 as the worst and best values of the Weibull distribution index. It indicates a $31 \%$ probability that the gantry crane will survive failures. The number of loading cycles for the eight cranes studied may be calculated from the analysis of the number of moves made by using the cranes in the loading and unloading activities. Each gantry crane is deployed to operations with at least five members of the group forming a gang in a shift per day. The target is that each gantry crane is expected to make seventeen moves per hour for a 12-hour work for a break. On average and from the information gathered from the workers in the port, 8 moves are often made per gantry crane. By analyzing this value in terms of operations for eleven hours, a total of $11 \times 8=88$ moves in achieved in a day per shift by a gang using the crane. With the two shifts operated per day, about 176 moves were achieved for a crane per day for two shifts. Furthermore, for the eight gantry cranes, 1408 moves are feasible for a day of two shifts. For a year of 365 days, the total number of moves is 513,920, Weighted against what was indicated in Faltinova et al. (2018), the number of moves (loading cycles, p.13) was quoted as $t_{0}=1905802$. Our values are just about $26.97 \%$ of this. Although no detailed information was given about this in the paper, if the number of gantry cranes used is less or equal to eight then our results show underperformance necessitating re-engineering the system. 
Table 3. Weibull Distribution Equipment Failures with $\beta=0.5,1$, and 3

\begin{tabular}{|c|c|c|c|c|c|c|c|c|c|c|c|c|c|}
\hline \multirow[t]{2}{*}{$\mathrm{S} / \mathrm{N}$} & \multirow[t]{2}{*}{ DTM } & \multicolumn{4}{|c|}{$\beta=0.5$} & \multicolumn{4}{|c|}{$\beta=1$} & \multicolumn{4}{|c|}{$\beta=3$} \\
\hline & & PDF & $\mathrm{CDF}$ & $R(t)$ & $h(t)$ & PDF & $\mathrm{CDF}$ & $R(t)$ & $h(t)$ & PDF & $\mathrm{CDF}$ & $R(t)$ & $h(t)$ \\
\hline 1 & 6.54 & 0.03 & 0.48 & 0.52 & 0.05 & 0.65 & 0.35 & 0.65 & 0.03 & 0.03 & 0.08 & 0.92 & 0.04 \\
\hline 2 & 18.49 & 0.01 & 0.67 & 0.33 & 0.03 & 0.30 & 0.70 & 0.30 & 0.08 & 0.48 & 0.84 & 0.16 & 0.29 \\
\hline 3 & 21.00 & 0.09 & 0.61 & 0.31 & 0.03 & 0.25 & 0.75 & 0.26 & 0.09 & 0.27 & 0.93 & 0.07 & 0.38 \\
\hline 4 & 16.12 & 0.01 & 0.64 & 0.36 & 0.03 & 0.35 & 0.65 & 0.35 & 0.07 & 0.67 & 0.70 & 0.30 & 0.22 \\
\hline 5 & 20.37 & 0.09 & 0.69 & 0.31 & 0.28 & 0.26 & 0.74 & 0.26 & 0.09 & 0.03 & 0.91 & 0.09 & 0.36 \\
\hline 6 & 33.27 & 0.01 & 0.77 & 0.22 & 0.02 & 0.11 & 0.89 & 0.11 & 0.14 & 0.00003 & 0.10 & 0.90 & 0.95 \\
\hline 7 & 124.18 & 0.00066 & 0.94 & 0.06 & 0.01 & 0.00028 & 0.99 & 0.00028 & 0.54 & 0.00000 & 1.00 & 0.00 & 13.20 \\
\hline 8 & 68.05 & 0.002 & 0.88 & 0.12 & 0.02 & 0.11 & 0.99 & 0.11 & 0.29 & $3.55\left(10^{-39}\right)$ & 1.00 & 0.00 & 3.96 \\
\hline 9 & 17.04 & 0.01 & 0.65 & 0.35 & 0.03 & 0.33 & 0.67 & 0.33 & 0.07 & 0.06 & 0.76 & 0.24 & 0.25 \\
\hline 10 & 25.05 & 0.007 & 0.72 & 0.28 & 0.03 & 0.19 & 0.81 & 0.19 & 0.11 & 0.006 & 0.99 & 0.01 & 0.54 \\
\hline 11 & 20.34 & 0.01 & 0.69 & 0.31 & 0.03 & 0.26 & 0.74 & 0.26 & 0.09 & 0.03 & 0.91 & 0.09 & 0.35 \\
\hline 12 & 13.18 & 0.01 & 0.61 & 0.39 & 0.04 & 0.42 & 0.58 & 0.42 & 0.06 & 0.08 & 0.48 & 0.52 & 0.15 \\
\hline 13 & 23.05 & 0.01 & 0.71 & 0.29 & 0.03 & 0.22 & 0.78 & 0.22 & 0.10 & 0.01 & 0.97 & 0.03 & 0.45 \\
\hline 14 & 35.24 & 0.005 & 0.78 & 0.22 & 0.02 & 0.98 & 0.90 & 0.98 & 0.15 & 0.000004 & 0.10 & 0.90 & 1.06 \\
\hline 15 & 24.44 & 0.01 & 0.72 & 0.28 & 0.03 & 0.20 & 0.80 & 0.20 & 0.11 & 0.008 & 0.98 & 0.02 & 0.51 \\
\hline 16 & 21.26 & 0.01 & 0.69 & 0.31 & 0.03 & 0.25 & 0.75 & 0.25 & 0.09 & 0.02 & 0.94 & 0.06 & 0.39 \\
\hline 17 & 14.39 & 0.01 & 0.62 & 0.38 & 0.03 & 0.39 & 0.61 & 0.39 & 0.06 & 0.08 & 0.36 & 0.43 & 0.18 \\
\hline 18 & 26.09 & 0.01 & 0.73 & 0.27 & 0.03 & 0.18 & 0.82 & 0.18 & 0.11 & 0.004 & 0.99 & 0.006 & 0.58 \\
\hline 19 & 4.29 & 0.04 & 0.41 & 0.59 & 0.06 & 0.75 & 0.25 & 0.75 & 0.02 & 0.015 & 0.22 & 0.80 & 0.02 \\
\hline 20 & 21.13 & 0.01 & 0.69 & 0.31 & 0.03 & 0.25 & 0.75 & 0.25 & 0.09 & 0.03 & 0.93 & 0.07 & 0.38 \\
\hline 21 & 33.19 & 0.01 & 0.77 & 0.23 & 0.02 & 0.11 & 0.89 & 0.12 & 0.14 & 0.0003 & 1.00 & 0.00003 & 0.94 \\
\hline 22 & 58.41 & 0.002 & 0.86 & 0.14 & 0.02 & 0.02 & 0.98 & 0.02 & 0.25 & $5.92\left(10^{-25}\right)$ & 1.00 & 0.00 & 2.94 \\
\hline 23 & 22.30 & 0.01 & 0.70 & 0.30 & 0.03 & 0.23 & 0.77 & 0.23 & 0.10 & 0.02 & 0.96 & 0.04 & 0.43 \\
\hline 24 & 36.31 & 0.005 & 0.79 & 0.21 & 0.21 & 0.09 & 0.91 & 0.09 & 0.16 & 0.000001 & 0.10 & 0.90 & 0.000002 \\
\hline 25 & 22.17 & 0.008 & 0.70 & 0.30 & 0.03 & 0.23 & 0.77 & 0.23 & 0.10 & 0.02 & 0.96 & 0.04 & 0.42 \\
\hline 26 & 26.55 & 0.007 & 0.73 & 0.27 & 0.02 & 0.17 & 0.83 & 0.17 & 0.12 & 0.003 & 1.00 & 0.005 & 060 \\
\hline 27 & 19.18 & 0.01 & 0.67 & 0.33 & 0.03 & 0.28 & 0.72 & 0.28 & 0.08 & 0.04 & 0.87 & 0.13 & 0.31 \\
\hline 28 & 42.52 & 0.005 & 0.81 & 0.82 & 0.02 & 0.06 & 0.94 & 0.06 & 0.18 & $4.61\left(10^{-10}\right)$ & 0.10 & 0.90 & $5.12\left(10^{-10}\right)$ \\
\hline 29 & 52.16 & 0.003 & 0.84 & 0.16 & 0.02 & 0.03 & 0.97 & 0.03 & 0.23 & $6.07\left(10^{-18}\right)$ & 1.00 & 0.00 & 2.33 \\
\hline 30 & 51.02 & 0.003 & 0.84 & 0.16 & 0.02 & 0.03 & 0.97 & 0.03 & 0.22 & $7.79\left(10^{-17}\right)$ & 1.00 & 0.00 & 2.23 \\
\hline
\end{tabular}

Note: Downtime (hours) - DTM, probability density function - PDF, cumulative density function - CDF, reliability - $R(t)$, hazard rate $-h(t)$ 
Table 4. Rayleigh Distribution and Normal Distribution for Equipment Failures

\begin{tabular}{|c|c|c|c|c|c|c|c|c|c|}
\hline \multirow[t]{2}{*}{$\mathrm{S} / \mathrm{N}$} & \multirow[t]{2}{*}{ DTM } & \multicolumn{4}{|c|}{ Rayleigh distribution } & \multicolumn{4}{|c|}{ Normal distribution } \\
\hline & & PDF & $\mathrm{CDF}$ & $R(t)$ & $h(t)$ & PDF & $\mathrm{CDF}$ & $R(t)$ & $H(t)$ \\
\hline 1 & 6.54 & 0.0004 & 0.001 & 1.00 & 0.0004 & 0.02 & 0.14 & 0.86 & 0.02 \\
\hline 2 & 18.49 & 0.0012 & 0.01 & 0.99 & 0.0012 & 0.02 & 0.30 & 0.70 & 0.02 \\
\hline 3 & 21.00 & 0.0013 & 0.01 & 0.99 & 0.0014 & 0.01 & 0.34 & 0.66 & 0.06 \\
\hline 4 & 16.12 & 0.0010 & 0.01 & 0.99 & 0.0010 & 0.02 & 0.22 & 0.74 & 0.02 \\
\hline 5 & 20.37 & 0.0013 & 0.01 & 0.99 & 0.0013 & 0.02 & 0.32 & 0.67 & 0.03 \\
\hline 6 & 33.27 & 0.0021 & 0.04 & 0.96 & 0.0022 & 0.02 & 0.55 & 0.45 & 0.04 \\
\hline 7 & 124.18 & 0.0049 & 0.40 & 0.61 & 0.0081 & 0.02 & 1.00 & $1.71\left(10^{-05}\right)$ & 1131.10 \\
\hline 8 & 68.05 & 0.0038 & 0.14 & 0.86 & 0.0044 & 0.02 & 0.95 & 0.05 & 0.38 \\
\hline 9 & 17.04 & 0.0017 & 0.01 & 0.99 & 0.0016 & 0.02 & 0.27 & 0.73 & 0.02 \\
\hline 10 & 25.05 & 0.0016 & 0.02 & 0.98 & 0.0016 & 0.02 & 0.40 & 0.60 & 0.03 \\
\hline 11 & 20.34 & 0.0013 & 0.01 & 0.99 & 0.0013 & 0.02 & 0.33 & 0.67 & 0.03 \\
\hline 12 & 13.18 & 0.0085 & 0.01 & 0.99 & 0.0009 & 0.02 & 0.22 & 0.78 & 0.02 \\
\hline 13 & 23.05 & 0.0015 & 0.02 & 0.98 & 0.0015 & 0.02 & 0.37 & 0.63 & 0.03 \\
\hline 14 & 35.24 & 0.0022 & 0.04 & 0.96 & 0.0023 & 0.02 & 0.58 & 0.42 & 0.04 \\
\hline 15 & 24.44 & 0.0016 & 0.02 & 0.98 & 0.0016 & 0.02 & 0.39 & 0.61 & 0.03 \\
\hline 16 & 21.26 & 0.0014 & 0.01 & 0.99 & 0.0014 & 0.02 & 0.34 & 0.66 & 0.03 \\
\hline 17 & 14.39 & 0.0009 & 00.01 & 0.99 & 0.0009 & 0.02 & 0.24 & 0.76 & 0.02 \\
\hline 18 & 26.09 & 0.0017 & 0.02 & 0.98 & 0.0017 & 0.02 & 0.42 & 0.58 & 0.03 \\
\hline 19 & 4.29 & 0.0003 & 0.0006 & 1.00 & 0.0003 & 0.02 & 0.12 & 0.88 & 0.02 \\
\hline 20 & 21.13 & 0.00001 & 0.01 & 0.99 & 0.0014 & 0.02 & 0.34 & 0.66 & 0.03 \\
\hline 21 & 33.19 & 0.0016 & 0.04 & 0.96 & 0.0017 & 0.02 & 0.55 & 0.45 & 0.04 \\
\hline 22 & 58.41 & 0.0030 & 0.10 & 0.90 & 0.0038 & 0.02 & 0.89 & 0.11 & 0.17 \\
\hline 23 & 22.30 & 0.0010 & 0.02 & 0.98 & 0.0014 & 0.02 & 0.36 & 0.64 & 0.03 \\
\hline 24 & 36.31 & 0.0023 & 0.04 & 0.96 & 0.0024 & 0.02 & 0.60 & 0.40 & 0.04 \\
\hline 25 & 22.17 & 0.0014 & 0.02 & 0.98 & 0.0014 & 0.02 & 0.35 & 0.65 & 0.03 \\
\hline 26 & 26.55 & 0.0017 & 0.02 & 0.98 & 0.0017 & 0.02 & 0.43 & 0.57 & 0.03 \\
\hline 27 & 19.18 & 0.0012 & 0.01 & 0.99 & 0.0012 & 0.02 & 0.31 & 0.69 & 0.03 \\
\hline 28 & 42.52 & 0.0026 & 0.06 & 0.94 & 0.0028 & 0.02 & 0.70 & 0.30 & 0.06 \\
\hline 29 & 52.16 & 0.0031 & 0.08 & 0.92 & 0.0034 & 0.02 & 0.83 & 0.17 & 0.11 \\
\hline 30 & 51.02 & 0.0030 & 0.08 & 0.92 & 0.0033 & 0.02 & 0.82 & 0.18 & 0.10 \\
\hline
\end{tabular}

Note: Downtime (hours) - DTM, probability density function - PDF, cumulative density function - CDF, reliability - $R(t)$, hazard rate - $h(t)$ 


\subsection{Contribution of the Article}

To date, a considerable group of studies strives to understand the operational effectiveness of facilities used at the ports terminal. Although these studies offer some essential insights particularly regarding the simulation and modeling of the ports congestion and decongestion activities through loading and unloading parameters of the trucks and cranes, it devotes negligible attention to the maintenance parameters of the gantry crane, which is key equipment in container terminals. But failure data of real-life gantry cranes may be helpful to determine the capability of the plant and ability to respond quickly to loading and unloading requests in the context of huge demands from customers. The unique contribution of this paper is to model the failure characteristics of the gantry cranes in a container terminal using three models, including the Weibull distribution, the Rayleigh distribution, and the Normal distribution.

It establishes first, the shape and scale parameters and then determines the probability density function, cumulative density function, and the downtime characteristics of the equipment. Furthermore, the use of historical data covering thirty weeks was made and the development of the model with the application was declared feasible with the data obtained from a Nigerian company.

\section{CONCLUSIONS}

The lifetime estimation of a container terminal was conducted using three newly introduced methods to the container terminal operational evaluation literature - Weibull distribution, Rayleigh's distribution, and the Normal distribution. They were deployed to evaluate the real-life behavior of a port operating in southwestern Nigeria.

The statistical distributions, namely the Weibull distribution, Rayleigh's distribution, and Normal distribution were effective in evaluating the port's data. The mean downtime per week is 30.58 hours translating to $18.20 \%$ of the total available time for operations, which fairly competes with the historical downtime hours per week. However, two particular weeks were outliers in observations; they lie an irregular distance from others, which are 124.3 hours for week 7 and 68.0 hours for week 8 . The normal variation is at best up to 58.68 hours per week. For these two periods, perhaps there was a union strike with down tooling for most parts of the week and the workers cannot meet up with the standard. It could also be that an extended breakdown exists as the nature of fault was uncommon, beyond the technical expertise of the crew and expatriates might have been invited.

The Weibull function yielded results at $\beta=0.5,1$, and 3 . For the $\beta=0.5$, the Weibull results for PDF were least for week 7 at 0.00066 with corresponding CDF, $R(t)$ and $h(t)$ of $0.94,0.06$, and 0.01 , respectively. However, it was highest with a tie of 0.09 in weeks 3 and 5 . The corresponding CDF, $R(t)$ and $h(t)$ are $0.61,0.31$, and 0.03 for the first tie in the third week of evaluation and $0.69,0.31$, and 0.28 , respectively for the CDF, $R(t)$ and $h(t)$ during the $5^{\text {th }}$ week of data collection. For $\beta=1$, the Weibull results for PDF were least for week 7 also at 0.00028 with the corresponding CDF, $R(t)$ and $h(t)$ of 0.99 , 0.00028 , and 0.54 , respectively. Nonetheless, it was highest at 0.98 in week 14 . The corresponding $\mathrm{CDF}, R(t)$, and $h(t)$ are $0.90,0.98$, and 0.15 , respectively. For $\beta=3$, the Weibull results for PDF were least in week 8 with a value of $3.55 \times 10^{-39}$ with the corresponding values of $\mathrm{CDF}, R(t)$ and $h(t)$ of 1,0 , and 3.96, respectively. However, it was highest at 0.67 in week 4 with the corresponding values of CDF, $R(t)$ and $h(t)$ of $0.70,0.30$, and $0.22 \mathrm{~m}$ respectively. The results for the Rayleigh distribution show a least value of PDF 0.00001 in week 20 while the CDF, $R(t)$ and $h(t)$ values obtained were $0.01,0.99$, and 0.0014 , respectively. The highest value of PDF of 0.0085 was in week 12 with the corresponding values of $\mathrm{CDF}, R(t)$ and $h(t)$ of $0.01,0.99$, and 0.0009, respectively. For the normal distribution, the PDF was the same for the 30 weeks each at 0.02 . Judging based on the least CDF the obtained value of 0.12 in week 19 is noted. But the corresponding $R(t)$ and $h(t)$ are 0.88 and 0.02 , respectively. Going by the highest value of CDF, it was obtained as 1 , at week 7 while the corresponding $R(t)$ and $h(t)$ values are $1.71 \times 10^{-05}$ and 1131.10 , respectively. 


\section{REFERENCES}

Adenigbo, A. J. and Enyinda, C. A. (2016) "Operational Challenges of Cargo Handling Equipment at Terminals of Lagos Port Complex, Nigeria," FUTA Journal of Management and Technology, 1(2), pp. 105-111.

Chang, Y. T., Shin, S. H. and Lee, P. T. W. (2014) "Economic Impact of Port Sectors on South African Economy: An Input-Output Analysis," Transport Policy, 35, pp. 333340. doi: 10.1016/j.tranpol.2014.04.006.

Cigolini, R., Pero, M. and Rossi, T. (2013) "Sizing Off-shore Transhipment Systems: A Case Study in Maritime Dry-bulk Transportation," Production Planning and Control, 24(1), pp. 15-27. doi: 10.1080/09537287.2011.598266.

Emenyonu, U. M. et al. (2016) "Econometric Analysis of Seaport Development and Its Impact on the Economic Growth of Nigeria," International Journal of Advanced Research, 4(2), pp. 133-138. Available at: http://www.journalijar.com.

Evans, J. W., Kretschmann, D. E. and Green, D. W. (2019) Procedures for Estimation of Weibull Parameters. Madison.

Faltinova, E. et al. (2018) "Reliability Analysis of Crane Lifting Mechanism," Scientific Journal of Silesian University of Technology. Series Transport, 98, pp. 1526. doi: 10.20858/sjsutst.2018.98.2.

Iyer, K. C. and Nanyam, V. P. S. N. (2021) "Technical Efficiency Analysis of Container Terminals in India," Asian Journal of Shipping and Logistics, 37(1), pp. 61-72. doi: 10.1016/j.ajsl.2020.07.002.

Jouili, T. (2016) "The Role of Seaports in the Process of Economic Growth," Developing Country Studies, 6(2), pp. 64-69.

Keskinen, A., Annala, I. and Miedema, P. (2017) Maintenance of Automated Terminals.

Legato, P. and Mazza, R. M. (2001) "Berth Planning and Resources Optimisation at a Container Terminal via Discrete Event Simulation," European Journal of Operational Research, 133(3), pp. 537547. doi: 10.1016/S0377-2217(00)00200-9. Nishimura, E., Imai, A. and Papadimitriou, S.
(2001) "Berth Allocation Planning in the Public Berth System by Genetic Algorithms," European Journal of Operational Research, 131(2), pp. 282292. doi: 10.1016/S0377-2217(00)00128-4.

Nyema, S. M. (2014) "Factors Influencing Container Terminals Efficiency: a Case Study of Mombasa Entry Port," European Journal of Logistics Purchasing and Supply Chain Management, 2(3), pp. 39-78.

Onwuegbuchunam, D. E. (2018) “Assessing Port Governance, Devolution and Terminal Performance in Nigeria," Logistics, 2(1), pp. 1-16. doi: 10.3390/logistics2010006.

Prpić-Oršić, J. et al. (2016) "The Influence of Route Choice and Operating Conditions on Fuel Consumption and $\mathrm{CO} 2$ Emission of Ships," Journal of Marine Science and Technology, 21(3), pp. 434-457. doi: 10.1007/s00773-015-0367-5.

Psaraftis, H. N. and Kontovas, C. A. (2014) "Ship Speed Optimization: Concepts, Models and Combined Speed-routing Scenarios," Transportation Research Part C: Emerging Technologies, 44, pp. 52-69. doi: 10.1016/j.trc.2014.03.001.

Sharapiyeva, M. D., Antoni, A. and Yessenzhigitova, R. (2019) "The Impact of Port Transport-logistics Infrastructure and LPI for Economic Growth: On the Example of Landlocked Countries," Multidisciplinary Scientific Journal of Maritime Research, 33(1), pp. 63-75. doi: 10.31217/p.33.1.7.

Van Vianen, T. A. et al. (2012) "Simulation-based Operational Control of a Dry Bulk Terminal," in Proceedings of 2012 9th IEEE International Conference on Networking, Sensing and Control, ICNSC 2012. Beijing: IEEE, pp. 73-78. doi: 10.1109/ICNSC.2012.6204894.

Yeo, G. T., Thai, V. V. and Roh, S. Y. (2015) “An Analysis of Port Service Quality and Customer Satisfaction: The Case of Korean Container Ports," Asian Journal of Shipping and Logistics, 31(4), pp. 437-447. doi: 10.1016/j.ajsl.2016.01.002.

Yin, X. F., Khoo, L. P. and Chen, C.-H. (2011) “A Distributed Agent System for Port Planning 
Versi Online:

http://journal.ubm.ac.id/index.php/jiems

DOI: 10.30813/jiems.v14i1.2362

Hasil Penelitian

and Scheduling," Advanced Engineering

Informatics, 25(3), pp. 403-412. doi:

10.1016/j.aei.2010.10.004.
Journal of Industrial Engineering and Management Systems

Vol. 14, No. 1, 8-18, 2021

ISSN 1979-1720

E-ISSN 2579-8154

18 | J I E M S 